\title{
Dylematy metodologiczne badań kultury politycznej w Internecie
}

$B^{2}$ adania nad nowymi technologiami, w tym Internetem, ponad dekadę temu zostały określone mianem najszybciej rozwijającego się pola badawczego nauk społecznych $^{1}$. Z tego powodu, konieczne stało się opracowanie standaryzowanego sposobu badania tego nowego zjawiska na potrzeby nauk społecznych. Niniejszy tekst stanowi próbę odpowiedzi na pytanie o adekwatność stosowanych narzędzi badawczych do badań zjawisk społecznych w Internecie, w tym badań kultury politycznej ${ }^{2}$. Rozważany jest problem, w jakim stopniu klasyczne metody badań empirycznych ${ }^{3}$ mogą zostać zastosowane $\mathrm{w}$ badaniach tego zjawiska, a w jakim muszą lub powinny one zostać zmodyfikowane lub - nawet - odrzucone.

Kluczową kwestię stanowi rozstrzygnięcie, w jakim stopniu Internet stanowi odrębną sferę rzeczywistości wymagającą modyfikacji, rozszerzenia lub zastosowania innych niż dotychczasowe metod badawczych. Wyjątkowość Internetu podkreśla nazwa, używana powszechnie - tak w mowie potocznej, jak też w literaturze, publicystyce czy piśmiennictwie naukowym na jego określenie - wirtualna rzeczywistość. Użycie słowa „rzeczywistość” nadaje wysoki status fenomenowi Internetu, bowiem nie tylko wskazuje, że jest to odrębny i rządzący się swoim prawami obszar, lecz przede wszystkim zestawia go i sugeruje tożsamy status ze sferą stanowiącą jego dopełnienie logiczne, którą nazwać można (z braku innego dla niej określenia) - rzeczywistością fizyczną, a więc światem materialnym, tym co nas otacza, determinuje, w czym funkcjonujemy i żyjemy. Odpowiedź na pytanie o sens i adekwatność klasycznych metod empirycznych w eksploracji Internetu może zostać najpełniej udzielona na podstawie analizy porównawczej parametrów obu rzeczywistości - wirtualnej i fizycznej; rozważany jest tu podstawowy problem filozoficzny, odnoszący się do ontologii.

W jakim stopniu parametry ontologiczne obu rzeczywistości: wirtualnej i fizycznej są sobie tożsame? Jeśli te rzeczywistości są tożsame lub jeśli różnice są nieznaczne, wówczas

\footnotetext{
${ }^{1}$ P. Lyman, N. Wakeford, Going Into the (Virtual) Field, „American Behavioral Scientist” 1999, vol. 43, nr 3, s. 359.

${ }^{2} \mathrm{Na}$ potrzeby niniejszego artykułu przyjęto następującą, szeroką, powszechną w polskiej politologii definicję kultury politycznej utożsamiającą to zjawisko z wiedzą o polityce (komponent kognitywny), uznawanymi wartościami (komponent aksjonormatywny), oceną funkcjonowania tego co polityczne (komponent afektywny) oraz określonymi zachowaniami w sferze polityki, w tym tworzeniem określonych artefaktów (komponent behawioralny). Dyskusja na ten temat oraz oryginalna regulująco-projektująca definicja kultury politycznej została wyczerpująco przedstawiona w: J. Garlicki, Kultura polityczna młodzieży studenckiej, Warszawa 1991, s. 11-31. Podkreślić należy, że celem niniejszego tekstu nie są rozważania nad zakresem i treścią tego pojęcia - wyżej przedstawione ujęcie jest wystarczające, by określić obszar badań. Przyjęto definicję najszerszą, najbardziej pojemną, obejmującą największy zakres zjawisk, które potencjalnie mogą znaleźć się w sferze zainteresowań badacza kultury politycznej.

${ }^{3}$ Pojęcie klasycznych metod badań empirycznych używane jest na określenie ugruntowanych i szeroko stosowanych w naukach społecznych metod i technik badań takich jak: sondaże (zarówno twarzą w twarz, jak i te prowadzone telefonicznie), indywidualne wywiady pogłębione, grupowe wywiady zogniskowane czy obserwacja. Słowo „klasyczne” ma wskazać fakt, że metody te tworzyły się i kształtowały poza Internetem.
} 
w pełni zasadne będzie zastosowanie dotychczas wypracowanych w naukach społecznych narzędzi badawczych - jeśli nie, konieczne wydaje się zadanie pytań o zakres ich modyfikacji. Zarówno rzeczywistość internetową jak również rzeczywistość fizyczną można opisać za pomocą porównywalnych parametrów. Pomiędzy tymi dwoma rzeczywistościami dają się wyróżnić zarówno podobieństwa, jak też różnice. Istnieje bogata literatura przedmiotu na ten temat, tworzą się odrębne subdyscypliny badawcze na przykład informatyka społeczna ${ }^{4}$, socjologia Internetu, cybersocjologia lub cyberpsychologia ${ }^{5}$. Analiza literatury przedmiotu pozwala na wyodrębnienie szeregu różnic i podobieństw w zakresie parametrów ontologicznych rzeczywistości wirtualnej i rzeczywistości fizycznej. Przede wszystkim należy zwrócić uwagę na odmienność reguł funkcjonowania podstawowych zmiennych ontologicznych: przestrzeni i czasu, określaną mianem delokalizacji lub teleimmersji. Internet modyfikuje także zmienną czasu - dokonuje jego rozciągania i koncentracji (time stretching and condensation). Przestrzeń wirtualnej rzeczywistości jest płynna i niepewna ${ }^{6}$. Ważną cechą wirtualnej rzeczywistości jest także fakt, że nie przebywa się w niej fizycznie, a obecność ma charakter symboliczny i zapośredniczony. Odbiór zmysłowy Internetu także jest odmienny niż odbiór rzeczywistości fizycznej; mówi się w literaturze przedmiotu o ograniczeniu doświadczeń sensorycznych: środowisko wirtualne zakłada wykorzystanie przede wszystkim zmysłu wzroku. Ograniczone znaczenie ma zmysł słuchu, natomiast pozostałe zmysły - węch, dotyk, zmysł równowagi są eliminowane. Ważną grupę różnic pomiędzy rzeczywistościami stanowią parametry socjopsychologiczne ${ }^{7}$ : Internet zakreśla o wiele większą sferę wolności jednostkowej niż rzeczywistość fizyczna ze względu na wyzwolenie jego użytkownika od faktycznie pełnionych ról, względną anonimowość, możliwość niemal dowolnej symulacji i eksperymentu w zakresie tożsamości (zjawisko to identyfikuje się w literaturze przedmiotu jako płynność tożsamości - identity flexibility) ${ }^{8}$. Użytkownik Internetu ma możność swobodnej interakcji lub prawa do jej braku, sam wybiera formę i stopień aktywności z otoczeniem, nie jest mu ona wyznaczana przez kontekst społeczny lub rodzaj współuczestników. Rzeczywistość wirtualna charakteryzuje się także znacznie większą potencjalną dostępnością kontaktów, a dzięki zaawansowanym opcjom wyszukiwania, filtrowania, możliwe staje się komunikowanie $z$ dokładnie określonymi osobami bądź grupami. Ponadto powoduje ona spłaszczenie statusów poszczególnych użytkowników. Internet jest również przestrzenią informacyjną, zbiornikiem informacji o pojemności, złożoności i dostępności nieporównywalnej z dotychczasowymi zbiorami informacji. W tym zakresie Internet cechuje coś, co można określić „,pa-

\footnotetext{
${ }^{4}$ Termin ten wprowadził i wypromował Rob Kling, amerykański uczony, Dyrektor Centrum Informatyki Społecznej w Indiana University. Szerzej na temat informatyki społecznej w: S. Sawyer, H. Rosenbaum, Social Informatics in the Information Sciences: Current Activities and Emerging Directions, „Informing Science” 2000, vol. 3, nr 2, s. 89-95.

${ }^{5}$ A. Kubczak, Cybersocjologia? Internet jako przedmiot zainteresowania socjologów, w: Polskie doświadczenia $w$ kształtowaniu społeczeństwa informacyjnego: dylematy cywilizacyjno-kulturowe, Kraków 2002, s. 183-190 oraz D. Batorski, K. Olechnicki, Wprowadzenie do socjologii internetu, „Studia Socjologiczne” 2007, vol. 186, nr 3, s. 5-14; J. R. Suler, The First Decade of CyberPsychology, 2006, http://users.rider.edu/ suler/psycyber/decade.html, 8.09.2012.

${ }^{6}$ Zjawisko, gdzie normą jest zmiana, a procedury, procesy i obiekty są nietrwałe, efemeryczne Lev Manovich nazywa wariancyjnością. L. Manovich, Język nowych mediów, Warszawa 2006, s. 91-120.

7 J. R. Suler, The Basic Psychological Features of Cyberspace. Elements of a Cyberpsychology Model, 1996 (2002), http://users.rider.edu/ suler/psycyber/basicfeat.html, 8.09.2012.

8 J. R. Suler, Identity Management in Cyberspace, ,Journal of Applied Psychoanalytic Studies” 2002, nr 4, s. 455-460; J. R. Suler, Presence in Cyberspace, 2003, http://users.rider.edu/ $\sim$ suler/psycyber/presence.html, 8.09.2012.
} 
mięcią absolutną" - wszystkie informacje i zdarzenia są zachowywane i przechowywane (permanent records). Rzeczywistość wirtualna - w porównaniu z rzeczywistością fizyczną - charakteryzuje się hiperdystrybucją i hiperprodukcją informacji, informacja ta jest nieustrukturyzowana, jej ilość uniemożliwia ogarnięcie jej przez jakąkolwiek jednostkę, a poziom jej jakości jest często nierozpoznawalny. Tę sytuację Stanisław Lem określał mianem bomby megabitowej ${ }^{9}$, a David Shenk ${ }^{10}$ i Ryszard Tadeusiewicz ${ }^{11}$ - smogu informacyjnego (data smog). Wirtualna rzeczywistość czyni informacje o jednostkach i grupach nieporównywalnie bardziej dostępnymi niż kiedykolwiek w przeszłości, co uwiarygodnia tezę Michela Foucaulta, że nowoczesne państwo rezygnuje z przemocy fizycznej wobec obywateli na rzecz ich nadzorowania ${ }^{12}$. W tym kontekście rozwijane są alarmujące koncepcje totalitaryzmu opartego na technologii - państwa nadzoru czy Superpanoptykonu ${ }^{13}$, a Alvin Toffler głosi zmianę władzy - przemoc i zasoby finansowe przestają być czynnikami kontroli obywateli, a ich miejsce zajmuje informacja. Istotnym parametrem ontologicznym rzeczywistości wirtualnej jest potencjalny brak kontroli nad informacją (w publicystyce używa się nazwy „efekt Streisand” lub „efekt Pana Andrzeja"14). Ważną cechą rzeczywistości wirtualnej jest fakt, że łatwo w niej informacje zmanipulować i zniekształcić - ta rzeczywistość przy odpowiednim nakładzie sił i środków może być kształtowana niemal dowolnie. Rzeczywistość wirtualna jest rzeczywistością wielokanałową - właściwie można mówić, że składa się z wielu odrębnych wirtualnych rzeczywistości. Fakt tej wielości, odmienne konteksty poznawcze i pełnione funkcje rodzą wśród użytkowników różne interpretacje i nawyki, odmienne doświadczanie przestrzeni informacyjnej, a co za tym idzie tworzy się (częściowa) nieporównywalność doświadczeń związanych z informacją i wiedzą. Brak jest także skryptów poznawczych służących selekcji, interpretacji, rozpoznawaniu i przetwarzaniu informacji. Obie przestrzenie - wirtualna i fizyczna - obok opisanych wyżej różnic mają też wiele podobieństw: są przepełnione informacjami, obie charakteryzują się przyspieszeniem i pełnią te same funkcje - społeczne, komunikacyjne, informacyjne.

Powyższe rozważania wskazują, że w ograniczonym stopniu rzeczywistość wirtualna może być rozpatrywana jako ekstensja i kontynuacja rzeczywistości fizycznej, w znacznym stopniu jako jej modyfikacja i zmultiplikowanie jej możliwości i właściwości. Wynika z tego konieczność stosowania zmodyfikowanych sposobów badania i analizowania tej rzeczywistości. Konieczne jest przewartościowanie i transformacja dotychczasowej epistemologii w odniesieniu do rzeczywistości wirtualnej - Internetu. W dalszej części znalazła się próba odpowiedzi na pytanie czy i w jakim stopniu klasyczne, uznane narzędzia empiryczne

\footnotetext{
${ }^{9}$ S. Lem, Bomba megabitowa, Kraków 1999; T. Fiałkowski, S. Lem, Świat na krawędzi, Kraków 2007.

${ }^{10}$ D. Shenk, Data Smog. Surviving the information glut, Nowy Jork 1997, s. 27-28.

${ }^{11}$ R. Tadeusiewicz, $W$ dymie $i$ we mgle..., „ComputerWorld” 1999, nr 37, s. 60-62.

${ }^{12}$ M. Foucault, Nadzorować i karać, Warszawa 1998.

${ }^{13}$ D. Lyon, The Electronic Eye. The Rise of Surveillance Society, Minneapolis 1994, s. 37.

${ }^{14}$ Efekt Streisand dotyczy aktorki - Barbary Streisand wbrew woli której ujawniona i rozpowszechniona została satelitarna fotografia jej posesji. Szerzej na ten temat: The Streisand Effect: When Internet Censorship Backfires, „Complex Pop Culture” 2009, http://www.complex.com/pop-culture/2009/07/the-streisand-effect-when-internet-censorship-backfires, 8.09.2012. Z kolei ,efekt Pana Andrzeja” to rodzimy odpowiednik zjawiska rozpowszechniania informacji wbrew woli samego zainteresowanego. Doświadczył tego pasłęcki policjant, aspirant Janusz Ławrynowicz, z którego wizerunku, wbrew jego woli uczyniono popularny mem krzywdząco przypisujący mu nieposiadane przezeń negatywne cechy. mn//mat/k, Zrobili z niego „,największego prostaka”. Pyta: Dlaczego ja?, „TVN24”, 8.08.2012, http://www.tvn24.pl/zrobili-z-niego-najwiekszego-prostaka-pyta-dlaczego-ja,269944,s.html, 8.09.2012.
} 


\section{służące do poznawania i analizy rzeczywistości fizycznej mogą być zastosowane w bada- niach Internetu?}

W badaniach kultury politycznej - zarówno rzeczywistości nazwanej fizyczną jak też rzeczywistości wirtualnej - możemy wyróżnić cztery następujące obszary zainteresowań: 1) badania opinii, 2) badania zachowań, 3) badania wytworów kultury politycznej (materialnych i niematerialnych). Ponadto istnieje obszar specyficzny dla wirtualnej rzeczywistości, niemający odpowiednika w rzeczywistości fizycznej, a istotny dla zrozumienia funkcjonującej tam kultury politycznej - chodzi o strukturę Internetu. Badanie opinii internautów (1) opiera się na ugruntowanych $\mathrm{w}$ internetowej praktyce badawczej technikach pomiaru poglądów i przekonań badanych. W tym celu używa się zarówno technik jakościowych, jak też ilościowych. Badania opinii są najczęściej wykorzystywanymi technikami badawczymi poza Internetem. Badania zachowań internautów (2) skupiają się na konkretnych jednostkach ludzkich, jednak w przeciwieństwie do badań opinii internautów nie wymagają one interakcji z badanym. Badacza interesują konkretne działania podejmowane przez użytkowników Internetu. Badanie tego obszaru może się odbywać za pomocą obserwacji lub eksperymentu. W pierwszym przypadku przedmiotem zainteresowania jest naturalny bieg wydarzeń, a konkretnie określone zachowania badanych. W drugim przypadku badacz dokonuje ingerencji w naturalny bieg rzeczy w celu wywołania i odnotowania przewidywanych reakcji. Czyni się to najczęściej w warunkach laboratoryjnych. Badania kulturowytworów i subkultur (3). W Internecie powstają nieustannie produkty kultury: komentarze, publicystyka, dyskusje moderowane i niemoderowane, strony i portale, korespondencja prywatna w postaci synchronicznej (czat) i asynchronicznej (e-mail), pamiętniki (w postaci różnych odmian blogów), a nawet wykreowane postaci (w grach), tożsamości (w komunikacji internetowej), a także światy i obiekty w tych światach. Ten materiał - twory kultury - może przyjmować postać tekstów, dźwięku, obrazu i filmu. Część z nich jest świadectwem postaw politycznych internautów. W celu badania tych fenomenów stosowane są badania określane mianem etnograficznych. Badania struktury Internetu (4). Struktura rzeczywistości wirtualnej jest fenomenem unikalnym, bowiem obok fizycznych parametrów, ma również obiektywnie mierzalne parametry społeczne. Tworzy je wzajemny układ treści znajdujących się w Internecie - stron www, forów dyskusyjnych, blogów, mikroblogów, kont w serwisach społecznościowych oraz intensywności i rodzaju połączeń między nimi. Przedmiotem badań jest system wzajemnych powiązań pomiędzy nimi, kontekst społeczny i polityczny świadczący o wzajemnych sympatiach, antypatiach, treściach o wysokiej i niskiej popularności. Powiązania takie, co prawda występują w rzeczywistości fizycznej, lecz nie są możliwe do zbadania ilościowo i w prosty sposób.

1. Do badania opinii internautów zaadaptowano klasyczną ilościową metodę badawczą wywiadów kwestionariuszowych (Paper And Pencil Interviews - PAPI, Face To Face - F2F) oraz badań ankietowych. Pierwsza z nich była od lat siedemdziesiątych XX wieku intensywnie rozwijana także w postaci wywiadów telefonicznych wspomaganych komputerowo (Computer Assisted Telephone Interviews - CATI), a w latach dziewięćdziesiątych jako wywiady kwestionariuszowe wspomagane komputerowo (Computer Assisted Personal Interviews). Dwie ostatnie wymienione metody stanowią nadbudowę poprzednich i jednocześnie ich modyfikację do wymogów stawianych przez oprogramowanie komputerowe. Na podstawie tych technik badawczych opracowano wywiady online (Computer Asissted Web Interviews - CAWI). Początkowo występowały jej liczne odmiany, lecz przyjęła się i upowszechniła forma polegająca na zamieszczeniu na stronie internetowej ankiety wypełnianej przez respondenta. Respondent trafiający na taką stronę odczytuje pytania i zaznacza standaryzowane 
predefiniowane odpowiedzi. Do badań opinii służą także metody jakościowe. Szczególnie popularne i metodologicznie rozwinięte są dwie z nich: zogniskowane wywiady grupowe (Focus Group Interviews) oraz indywidualne wywiady pogłębione (Individual In-Depth Interviews). Pierwsza z nich przyjęła miano wirtualnych zogniskowanych wywiadów grupowych (Virtual Focus Group Interviews), a druga wirtualnych indywidualnych wywiadów pogłębionych (Virtual Individual In-Depth Interviews).

Badania typu CAWI stanowią modyfikację badań kwestionariuszowych i ankiet klasycznych i w pewnym sensie metodologiczne nadużycie, bowiem nazwą nawiązują one do wywiadów kwestionariuszowych (sugerują obecność pośrednika między kwestionariuszem a respondentem, a więc udział ankietera), natomiast z punktu widzenia metodologicznego są badaniami ankietowymi (tego pośrednika w rzeczywistości nie ma, respondent samodzielnie wypełnia ankietę). W istocie, jeśliby rygorystycznie potraktować nazewnictwo, a badania CAWI miałyby być dosłownie wywiadem online, to powinny się one odbywać z użyciem transmisji głosowej przez Internet (VoIP) i wówczas byłyby wywiadami telefonicznymi realizowanymi przez Internet lub z użyciem transmisji obrazu - za pomocą kamer internetowych dokumentujących również zachowania niewerbalne respondenta (to ostatnie rozwiązanie byłoby najbliższe klasycznemu wywiadowi PAPI). Problem jest istotny, bowiem wprowadza w błąd, sugerując, że technika ta spełnia wyższe niż ankieta standardy metodologiczne (m.in. znaczniejszy stopień zwrotów, większa kontrola nad przebiegiem interakcji). Drugi adaptacyjny problem metodologiczny stanowi dobór próby. Losowy lub losowo-warstwowy dobór próby umożliwiający uogólnianie zebranych wyników na populację jest dobrze rozwinięty w przypadku klasycznych badań ilościowych, natomiast trudny do zrealizowania lub wręcz niemożliwy w przypadku badań CAWI. O ile istnieje operat losowania jednostek, gospodarstw domowych, przedsiębiorstw czy instytucji publicznych dla badań drogą telefoniczną (numer telefonu) oraz osobiście (adres), o tyle w przypadku badań CAWI takiego pełnego operatu nie ma. Oznacza to konieczność poszukiwania sposobów doboru próby umożliwiających wnioskowanie na populację. Taką metodologiczną modyfikację znaleziono: polega ona na tworzeniu tak zwanych paneli internetowych, to jest zbiorów uprzednio zrekrutowanych użytkowników Internetu, którzy wyrazili zgodę na udział w badaniach. Panele te, w zależności od sposobu rekrutacji, zapewniają zróżnicowaną reprezentatywność: najniższy jej poziom zapewnia rekrutacja prowadzona online. Panel taki nie jest reprezentatywny dla ogółu użytkowników Internetu, a co najwyżej dla niektórych - dobranych zgodnie z regułami sztuki - grup. Nazywa się go panelem srebrnym. Z kolei panel umożliwiający ekstrapolowanie wyników badania na ogół internautów tworzony jest na podstawie rekrutacji poza Internetem. Określa się go mianem panelu złotego. Istnieje jeszcze potencjalnie trzeci typ panelu - umożliwiający ekstrapolowanie wyników badania na populację generalną, na przykład ogółu dorosłych Polaków (tzw. panel platynowy) ${ }^{15}$. W praktyce badawczej jeszcze nie występuje, bowiem wymaga znacznej penetracji populacji generalnej dostępem do Internetu, na poziomie co najmniej 50 lub nawet 75 proc. ${ }^{16}$ Najbardziej znanymi i największymi panelami na świecie są: American Consumer Opinion firmy Decision Analyst, Bases e-panel, NPD Online, Greenfield Online czy Harris Interactive Poll. Panele te obejmują od kilkudziesięciu tysięcy do kilku milionów sprofilowanych respondentów. Dobór z panelu nie jest jednak doborem

\footnotetext{
${ }^{15}$ M. Sobocińska, Panele internetowe, w: Badania marketingowe. Teoria i praktyka, Warszawa 2005, s. 142.

${ }^{16}$ K. Sobieszczek, Problem błędu braku odpowiedzi w badaniach internetowych, w: Re: Internet - spoleczne aspekty medium, red. Ł. Jonak, P. Mazurek, M. Olcoń, A. Przybylska, A. Tarkowski, J. Zając, Warszawa 2006, s. $372-376$.
} 
losowym, ani losowo-warstwowym. Uzyskujemy na podstawie doboru kwotowego dobór quasi-reprezentatywny i taki jest dla badaczy opinii w Internecie satysfakcjonujący, bo jedyny możliwy. Polega na doborze z panelu jednostek analizy o takich zmiennych socjodemograficznych, by zestawione razem stanowiły miniaturę badanej populacji. Z punktu widzenia ortodoksyjnych zasad doboru próby wnioskowanie na podstawie wyników takiego badania na populację internautów, a tym bardziej ogólną jest niedozwolone, mimo to jest powszechną praktyką badawczą. Badanie typu CAWI lokuje się pomiędzy ankietą a wywiadem w zakresie następujących parametrów: optymalnego (dla respondenta) czasu trwania wywiadu oraz wiarygodności zbieranych danych. Badania CAWI mogą być dłuższe (pod względem liczby pytań) niż badania ankietowe, lecz krótsze niż wywiady kwestionariuszowe. Z drugiej strony badania typu CAWI nie mogą równać się pod względem długości trwania $\mathrm{z}$ wywiadami typu PAPI, w tych drugich obecność ankietera i konkretna sytuacja interakcji społecznej jest czynnikiem motywującym. Czas trwania fazy realizacji terenowej badania CAWI jest o wiele krótszy niż badań PAPI czy CATI. Szybsze jest także przygotowanie kwestionariusza badania, a następnie agregacja, rekonfiguracja i przygotowanie bazy danych surowych z badania. Zaleta jest szybkość uzyskania odpowiedzi (wskazuje się, że zaledwie w ciagu doby lub kilku dób, zdarzają się doniesienia o zrealizowaniu całości próby zaledwie w kilka godzin) ${ }^{17}$. Ponadto przeprowadzenie tego typu badania jest kilkukrotnie tańsze niż wykonanie badania PAPI, a parokrotnie tańsze niż badania CATI. Są to jednak zalety, które są jednocześnie źródłem wad. Niskie nakłady finansowe i krótki czas badania przysparzają takich kłopotów jak wysoki stopień ankiet przerwanych, niski stopień zwrotów oraz swoista dewaluacja tej techniki badawczej ze względu na niewysokie koszty jej wdrożenia i stosowanie przez podmioty nieposiadające właściwego zaplecza metodologicznego. Wskazać należy także na inne związane z parametrami ontologicznymi wirtualnej rzeczywistości cechy tych badań - nieinwazyjność tej techniki, a dzięki temu wyższy komfort respondenta i większe zaufanie do niej dzięki poczuciu względnej anonimowości respondenta ${ }^{18}$. Dzięki temu badania CAWI o wiele lepiej nadają się do pomiaru kwestii trudnych, drażliwych, intymnych niż badania PAPI, a nawet $\mathrm{CATI}^{19}$. Badanie typu CAWI stanowią z metodologicznego punktu widzenia konstrukt lokujący się pomiędzy wywiadami kwestionariuszowymi a ankietami, łączący wady i zalety obu typów badań. Są to techniki badawcze najczęściej stosowane w Internecie, ich parametry metodologiczne są obszernie rozważane w polskojęzycznej i zagranicznej literaturze przedmiotu. Stosunkowo rzadko wykorzystywane są one w badaniach kultury politycznej. Na rodzimym gruncie stosunkowo najszerzej wykorzystał je zespół politologów Zakładu Socjologii i Psychologii Polityki (ZSiPP) Uniwersytetu Warszawskiego, który podjął tą metodą systematyczne badania kultury politycznej w latach 2010 i $2011^{20}$.

${ }^{17}$ Ch. Mann, F. Stewart, Internet Communication and Qualitative Research. A Handbook for Researching Online, Londyn-New Delhi 2000, s. 72; R. Mącik, Wykorzystanie Internetu w badaniach marketingowych, Lublin 2005, s. 109.

${ }^{18}$ M. Sobocińska, Zakres zastosowań badań marketingowych przez Internet, w: Badania marketingowe. Teoria i praktyka, red. K. Mazurek-Łopacińska, Warszawa 2005, s. 216.

${ }^{19}$ Szczególnie dobrze tę cechę Internetu ukazuje badanie CAWI zaprojektowane przez prof. Zbigniewa Izdebskiego, w którym uzyskano obszerne, szczegółowe informacje na temat aktywności seksualnej i zdrowia seksualnego dorosłych Polaków: Z. Izdebski, Seks Polaków w Internecie. Raport Polpharmy 2010, Centrum Badań Marketingowych Indicator na zlecenie Polpharmy, http://www.opzs.pl/uploads/assets/files/Seks_Polakow_w_Internecie_prezentacja.pdf, 8.09.2012.

${ }^{20}$ Badanie to, zrealizowane metodą CAWI, zatytułowano Kultura polityczna polskich Internautów. Wykonano dwa pomiary: 10-14 VI 2010 roku i 27 IX-5 X 2011 roku odpowiednio na próbach N=757 i N=720. Wyniki tych badań obszernie zaprezentowano w tomie 21 i tomie 26 „Studiów Politologicznych” wydawanych przez Instytut Nauk Politycznych UW. 
Wirtualne grupowe wywiady zogniskowane (VFGI) są właściwie namiastką klasycznej techniki FGI. Zdaniem części uczonych jest to odrębna metoda badania, która z badań fokusowych zachowała jedynie swoją nazwę ${ }^{21}$, niektórzy wprost nazywają technikę tę quasi-jakościową $^{22}$. Podstawowy zarzut wobec VFGI dotyczy socjopsychologicznego kontekstu ich prowadzenia. Podkreśla się, że opinia ma genezę społeczną, opinie są tworzone i wzmacniane w interakcji między rozmówcami - a w VFGI zjawisko takie (nazywa się je synergią) - nie występuje z racji braku kontaktu fizycznego, twarzą w twarz. VFGI w porównaniu z FGI ma o wiele słabszą dynamikę, występują trudności w utrzymaniu przez moderatora pełnej koncentracji uczestników, prowadzący nie ma kontroli nad uczestnikami. Wskazuje się, że nieobojętna jest także kwestia technicznych kompetencji badanych - słabiej posługujący się komputerem, Internetem mniej aktywnie w nich uczestniczą ${ }^{23}$. Podmioty takie jak Millward Brown International i Digital Marketing Service nie prowadzą tego typu badań podkreślając, że brak możliwości bezpośredniego kontaktu moderatora z grupą pozbawia taką dyskusję najbardziej charakterystycznych cech tej metody. Z drugiej strony firmy badawcze jak Greenfield Online, NFO Interactive, Harris Black International uznają, że w ten sposób można zbierać dane nieustępujące jakością badaniom fokusowym tradycyjnym ${ }^{24}$. Technika VFGI budzi liczne kontrowersje, a jej metodologia wymaga znacznego dopracowania. Odrębne parametry ontologiczne wirtualnej rzeczywistości wymuszają daleko idące zmiany i dogłębną refleksję nad zasadami stosowania tej techniki. Nie stawia to zasadności stosowania VFGI pod znakiem zapytania, lecz wyklucza prowadzenie i interpretację wyników tych badań jak klasycznych FGI. Tego typu badania mogą być realizowane w dwóch trybach: synchronicznym (real time focus groups) i asynchronicznym (bulletin board virtual focus groups). Synchroniczny VFGI polega na interakcji respondentów i moderatora w tym samym ściśle określonym czasie - prowadzony jest na ogół w formie czatu. Z kolei w asynchronicznym VFGI stosuje się forum internetowe zamiast czatu, co pozwala na odwiedziny tego miejsca przez uczestników badania i moderatora w różnym czasie. Na forum tym uczestnicy zamieszczają sekwencyjnie swoje wypowiedzi i komentują już zamieszczone. Warto zwrócić uwagę, że dotychczas prowadzone VFGI mają charakter tekstowy, badani i moderator posługują się w komunikowaniu niemal wyłącznie tekstem. Rozwijane są techniki badawcze, które umożliwiająjednocześnie komunikowanie za pomocą dźwięku i/lub obrazu. Technika ta jest dopiero in statu nascendi - wykorzystywana jest głównie w badaniach na potrzeby komercyjne, rzadziej w typowych badaniach naukowych, dla celów poznawczych. Nie odnotowano wykorzystania tej techniki do badań kultury politycznej poza jednym przypadkiem - badań w ramach projektu Formy i treści ekspresji kultury politycznej Polaków w Internecie w kampaniach wyborczych 2010 i 2011 roku. Badanie to przeprowadzono w dwóch trybach - synchronicznym i asynchronicznym. Do realizacji wywiadu synchronicznego wykorzystano internetowy darmowy czat tekstowy umożliwiający dyskusję w czasie rzeczywistym wszystkich uczestników badania. Z kolei wywiad asynchroniczny odbył się za pomocą - również darmowego - internetowego forum dyskusyjnego, co pozwoliło na wymianę zdań między badanymi w różnym

${ }^{21}$ Ch. Mann, F. Stewart, op. cit.; J. B. Walther, Computer Mediated Communication: Impersonal, Interpersonal, and Hyperpersonal Interaction, „Communication Research” 1996, vol. 23, nr 1, s. 3-13.

22 A. M. Nikodemska-Wołowik, Jakościowe badania marketingowe w Internecie-uzasadniony sceptycyzm, w: Marketing - koncepcje, badania, zarzqdzanie, red. L. Żabiński, K. Śliwińska, Warszawa 2002, s. 166.

${ }^{23}$ M. Olcoń, Zogniskowane wywiady grupowe online - charakterystyka techniki badawczej, w: Re: Internet - społeczne aspekty medium, red. Ł. Jonak, P. Mazurek, M. Olcoń, A. Przybylska, A. Tarkowski, J. Zając, Warszawa 2006, s. 406.

${ }^{24}$ R. Mącik, Wykorzystanie Internetu $w$ badaniach marketingowych, Lublin 2005, s. 140. 
czasie, w zależności od ich dyspozycyjności. Uczestnikami pomiarów byli polscy dziennikarze internetowi, blogerzy i komentatorzy polityczni ${ }^{25}$.

Podobne, lecz jednak nieco złagodzone zarzuty, można sformułować w stosunku do wirtualnych indywidualnych wywiadów pogłębionych. Badania typu VIDI nie wymagają koordynacji (zarówno pod względem organizacji, jak też socjopsychologicznej jego dynamiki) w takim zakresie jak VFGI. Jednak pod względem interakcyjnym wydają się niemal tożsame z klasycznym IDI. Nie odnotowano dotychczas tego typu badań dedykowanych badaniu kultury politycznej.

2. Badanie zachowań w wirtualnej rzeczywistości wymaga odmiennych narzędzi badawczych, a w mniejszym stopniu nowej metodologii. Parametry ontologiczne Internetu stwarzają niespotykane w rzeczywistości fizycznej możliwości badania użytkowników Internetu. Chodzi tu o możliwości techniczne tego medium. Jak wskazywano Internet charakteryzuje się „pamięcią absolutną”. W rzeczywistości fizycznej do badania zachowań jednostek używa się dwóch metod badawczych: obserwacji oraz eksperymentu. Mają one zastosowanie również w badaniu rzeczywistości wirtualnej. Szczególną techniką jest obserwacja - zyskuje ona w rzeczywistości wirtualnej zupełnie nową jakość dzięki przytoczonym wyżej właściwościom owej rzeczywistości. O ile metoda obserwacyjna realizowana w rzeczywistości fizycznej miała charakter jakościowy, a więc deskryptywny, o tyle obserwacja zachowań w rzeczywistości wirtualnej może mieć charakter zarówno jakościowy, jak też ilościowy.

W pierwszym przypadku - badań ruchu użytkowników Internetu - służą do tego takie metody badania jak analiza logów komputerów (serwerów, na których znajdują się treści zamieszczane w Internecie: na przykład strony internetowe czy strony serwisów społecznościowych). Wykonywane są trzy subtypy badania ruchu w Internecie: 1) skupione na stronach internetowych (site centric), gdzie zbierane są dane dotyczące ruchu użytkowników oraz innych podmiotów na danej stronie internetowej czy portalu; 2) zogniskowane na ruchu generowanym na serwerze (server centric), a więc zakres badanych podmiotów jest szerszy - na danym serwerze może znajdować się wiele tematycznych stron internetowych; 3) skoncentrowane na użytkowniku (user centric) - badające całokształt aktywności danego użytkownika lub grupy użytkowników w Internecie. Takie dane zbierane są również z użyciem oprogramowania spyware, gromadzącego dane niezależnie od woli użytkowników. Istnieje ponadto szereg wyspecjalizowanych ilościowych subtechnik badawczych służących badaniu ruchu użytkowników na stronach internetowych: mousetracking oraz clicktracking.

W przypadku konkretnych interakcji społecznych pomiędzy użytkownikami proces badawczy przebiega podobnie do klasycznych badań obserwacyjnych, z kilkoma jednak różnicami: 1) interakcje mają charakter przede wszystkim tekstowy, co z jednej strony ogranicza możliwości klasycznej obserwacji, z drugiej - umożliwia połączenie jej z rozbudowywanymi obecnie metodami analizy tekstu, dyskursu, dokumentów; 2) fakt, że informacje te są przede wszystkim tekstowe zawęża pola percepcyjne badacza - cały świat znaczeń symbolicznych (gesty, emocje) pozostaje poza jego percepcja; 3) „pamięć absolutna” Internetu umożliwia wykonywanie bardzo dokładnych i pełnych analiz. W przeciwieństwie do obserwacji klasycznej możliwość rejestracji interesujących badacza wydarzeń jest pełna a nie wycinkowa. $\mathrm{Z}$ jednej strony mamy do czynienia z nadmiarem danych, z drugiej - z możliwością przepro-

\footnotetext{
${ }^{25}$ Przeprowadzono łącznie trzy wirtualne wywiady zogniskowane: dwa synchroniczne, w których uczestniczyło trzech respondentów (odbył się 16 XI 2011 roku) oraz drugi liczący pięciu uczestników (2 XII 2011 roku). Zrealizowano również jeden wywiad asynchroniczny z dwunastoma uczestnikami w terminach od 15 XII 2011 do 18 I 2012 roku.
} 
wadzenia nad wyraz precyzyjnych analiz, jakich nie moglibyśmy przeprowadzić w badaniach rzeczywistości fizycznej.

Badania zachowań można też przeprowadzać w sztucznie stworzonych przez badacza warunkach lub też w warunkach naturalnych, jednak z nałożonym planem eksperymentalnym. Eksperyment w rzeczywistości wirtualnej można prowadzić na takich samych warunkach jak w rzeczywistości fizycznej. Jedyną istotną różnicą - jak wskazuje Kamil Henne - jest fakt, że eksperyment online zmniejsza zaangażowanie badanych w sytuację badawczą - już samo przybycie do laboratorium, czyli podjęcie wysiłku daje badanym większą motywację do wykonywania zadań, skupienia na nich ${ }^{26}$. Wydaje się, że metodologia eksperymentu nie wymaga istotnych modyfikacji. W Internecie pierwsze eksperymenty zaczęli prowadzić psychologowie w pierwszej połowie lat dziewięćdziesiątych. Obecnie badania eksperymentalne w Internecie prowadzone są głównie na gruncie psychologii (na przykład Ulf-Dietrich Reips i Ralph Lengler prowadzą laboratorium psychologiczne w Zurichu, w którym używana jest metoda eksperymentalna).

3. Badania kulturowytworów i subkultur. Do badania rzeczywistości wirtualnej powstała dedykowana metoda badawcza, która uzyskała w literaturze przedmiotu nazwę netnografia. Wprowadził ją kanadyjski uczony Robert V. Kozinets. Słowo „netnografia” jest zbitkiem słów, a jednocześnie skrótowcem. Pochodzi ono od słów Internet (skróconego do „,net”) oraz etnografia (ethonography) skróconego do „nography”. Zasadniczy przedmiot badań z użyciem netnografii stanowią przekazy tekstowe i graficzne zamieszczane w Interne$\mathrm{cie}^{27}$. Jako pierwszy analizy treści witryn internetowych podczas kampanii wyborczej do Izby Reprezentantów w Stanach Zjednoczonych w 1996 roku dokonał Brad Stone, który analizował funkcjonalność stron internetowych, oceniał zasoby informacyjne oraz ich estetykę i multimedialność ${ }^{28}$. Warto także przytoczyć badanie, którego celem było przekonanie się, czy uprawianie polityki w cyberprzestrzeni wytworzy nowe formy uczestnictwa w polityce, a także czy zredukuje koszty komunikowania politycznego z elektoratem szczególnie podczas kampanii wyborczych ${ }^{29}$. Na uwagę zasługuje studium Kevina A. Hilla i Johna E. Hughesa. Autorzy testują w hipotezę, czy Internet został ,skolonizowany” przez prawicę ${ }^{30}$. W 2000 roku Rachel Gibson i Stephen Ward dokonali udanej próby standaryzacji sposobów analizy stron www partii politycznych - uczynili to na przykładzie stron www australijskiej i brytyjskiej Partii Pracy ${ }^{31}$.

4. Szczególną odmianą, charakterystyczną dla wirtualnej rzeczywistości jest badanie struktury Internetu. Sieciowa analiza odnośników definiowana jest jako procedura badawcza polegająca na identyfikowaniu tematycznie połączonych zbiorów stron internetowych, ma charakter ilościowy, wykorzystuje głównie metody statystyczne oraz prezentacje danych w postaci grafów. Pojawiły się liczne propozycje zastosowań tej metody do badań w Internecie, jest ona coraz bardziej popularna wśród badaczy społecznych ${ }^{32}$. Na gruncie nauk politycznych metodę sieciowej analizy odnośników zaczęto stosować w połowie ubiegłej dekady.

${ }^{26} \mathrm{~K}$. Henne, Internet - nowa technika badań w psychologii, „Nowiny psychologiczne” 2004, nr 2, s. 17.

${ }^{27}$ R. V. Kozinets, Netnography. Doing Ethnographic Research Online, Los Angeles 2010, s. 60.

${ }^{28}$ B. Stone, Politics '96, ,Internet World” 1996, s. 44-50.

${ }^{29}$ M. Margolis, D. Resnick, Ch. Tu, Campaigning on the Internet: Parties and Candidates on the World Wide Web in the Primary Season, „Harvard International Journal of Press/Politics” 1997, vol. 2, nr 1, s. 59-78.

${ }^{30}$ K. A. Hill, J. E. Hughes, Cyberpolitics: Citizen activism in the age of the Internet, Oxford 1998.

${ }^{31}$ R. Gibson, S. Ward, op. cit., s. 308-314.

${ }^{32}$ H. W. Park, Hyperlink Network Analysis: A New Method for the Study of Social Structure on the Web, „Connections" 2003, vol. 25, nr 1, s. 50 . 
Jej standaryzację w politologii zawdzięczamy dwojgu australijskim badaczom społecznym - Robertowi Acklandowi i Rachel Gibson ${ }^{33}$. Autorzy ci przeanalizowali 27 stron www australijskich partii politycznych. Przykładem zastosowania zaproponowanej metodologii jest także ilościowe studium sieci ponad tysiąca blogów politycznych podczas kampanii prezydenckiej w 2004 roku w Stanach Zjednoczonych Lady Adamic i Natalie Glance. Zbadali oni charakterystykę powiązań pomiędzy liberalnymi i konserwatywnymi blogami amerykańskiej blogosfery ${ }^{34}$. Analogiczną metodologię zastosował na rodzimym gruncie Albert Hupa. Przedmiotem badania uczynił orientacje polityczne w Internecie, korzystając z metodologii i z terminologii analizy sieciowej ${ }^{35}$.

Metoda sieciowej analizy odnośników powinna być charakteryzowana i rozważana nie tylko na gruncie teoretycznym - ważnymi wymiarami pozwalającymi na zrozumienie, docenienie i zastosowanie tej metody są wymiar analityczny (stosowane narzędzia do obróbki zebranych danych) i wymiar techniczny (stosowane narzędzia do zbierania danych). W wymiarze teoretycznym metoda ta korzysta z ustaleń terminologicznych i procedur badawczych klasycznej analizy sieciowej; jej zastosowanie do nowego środowiska badawczego, jakim jest Internet, nie wymusza zmiany podejścia w tym wymiarze. Największe zmiany standardów prowadzenia analizy sieciowej dotyczą wymiaru technicznego. Badania prowadzone w Internecie wymagają odmiennych od dotychczasowych sposobów zbierania danych służących do analizy sieciowej. Gromadzenie danych odbywa się za pomocą specjalnych programów przeszukujących sieć według zadanego algorytmu. Programy te nazywane są pająkami sieciowymi (web spiders, spiders), pełzaczami (web crawlers) lub robotami sieciowymi albo indeksującymi (web robots, robots, bots) ${ }^{36}$. Programy te eksplorują strony internetowe, poruszając się w określonym przez użytkownika obszarze i mogą zbierać szczegółowe informacje na temat aktywności użytkowników. Na potrzeby projektu badawczego kierowanego przez Jana Garlickiego Kultura polityczna elit $w$ Internecie został opracowany własny program służący do zbierania danych - sieciowy pająk INPspider ${ }^{37}$. Duża ilość zbieranych danych oraz złożoność powiązań sieciowych skłania w wymiarze analitycznym do nieznacznej modyfikacji klasycznego podejścia badawczego - konieczne jest wykorzystanie bardziej zaawansowanych narzędzi analitycznych. Są to narzędzia informatyczne, które muszą spełniać dwojakie funkcje: po pierwsze, służyć statystycznej obróbce danych, po drugie, służyć do ich wizualizacji.

Internet pozwala na zastosowanie pełnego pakietu dostępnych w naukach społecznych narzędzi badawczych, jednak podobieństwo tych narzędzi - klasycznych i internetowych - jest

${ }^{33}$ R. Ackland, R. Gibson, Mapping Political Party Networks on the WWW, Centre for Social Research, 2004, s. 4, http://voson.anu.edu.au/papers/political_networks.pdf, 8.09.2012.

${ }^{34}$ L. Adamic, N. Glance, The Political Blogosphere and the 2004 U.S. Election: Divided They Blog, 2005, s. 1-16, http://www.blogpulse.com/papers/2005/AdamicGlanceBlogWWW.pdf, 8.09.2012.

${ }^{35}$ A. Hupa, Badania orientacji politycznych $w$ Internecie, „Studia Socjologiczne” 2007, vol. 186, nr 3, s. $115-143$.

${ }^{36}$ Rudymenty wiedzy na temat pająków sieciowych zawiera artykuł: G. Pant, P. Srinivasan, F. Menczer, Crawling the Web, 2004, s. 1-25, http://dollar.biz.uiowa.edu/ pant/Papers/crawling.pdf, 8.09.2012.

${ }^{37}$ Autorem programu INPspider (pierwszy człon nazwy to skrót jednostki, w której pracują badacze - Instytutu Nauk Politycznych) jest pracownik Katedry Informatyki Uniwersytetu Ekonomicznego w Katowicach mgr Artur Strzelecki. Pomysłodawcą merytorycznym projektu (w sensie zastosowania tego narzędzia informatycznego w politologii) jest autor niniejszego referatu. 
złudne. Najczęściej narzędzia te wymagają modyfikacji: metodologicznych i analitycznych, a rozpoznawanie ich właściwości nie zostało jeszcze zakończone. W najmniejszym stopniu wymagają modyfikacji do nowych warunków techniki badawcze służące ilościowym badaniom opinii internautów, zaś największego nakładu wymagają badania jakościowe opinii. Z kolei badania kulturowytworów oraz badania struktury Internetu wytworzyły swoiście dostosowaną do badań Internetu metodologię. Wszystkie stosowane w Internecie techniki badawcze wymagają metodologicznej refleksji oraz praktycznych testów porównawczych wyników badań - tylko wówczas będzie możliwe ich dostosowanie do potrzeb badań Internetu i właściwa kalibracja.

\section{Bibliografia}

Ackland R., Gibson R., Mapping Political Party Networks on the WWW, Centre for Social Research, Canberra 2004, http://voson.anu.edu.au/papers/political_networks.pdf.

Adamic L., Glance N., The Political Blogosphere and the 2004 U.S. Election: Divided They Blog, Pittsburgh 2005, http://www.blogpulse.com/papers/2005/AdamicGlanceBlogWWW.pdf.

Batorski D., Olechnicki K., Wprowadzenie do socjologii internetu, „Studia Socjologiczne” 2007, vol. 186, nr 3.

Foucault M., Nadzorować i karać. Narodziny więzienia, Wydawnictwo Fundacji „Altheia”, Warszawa 1998.

Garlicki J., Kultura polityczna młodzieży studenckiej, Państwowe Wydawnictwo Naukowe, Warszawa 1991.

Gregor B., Stawiszyński M., Wykorzystanie Internetu w badaniach panelowych rynku, w: Oblicza Internetu. Internet a globalne spoteczeństwo informacyjne, Wydawnictwo PWSZ, Elbląg 2005.

Henne K., Internet - nowa technika badań w psychologii, „Nowiny psychologiczne” 2004, nr 2.

Hill K. A., Hughes J. E., Cyberpolitics: Citizen activism in the age of the Internet, Rowman and Littlefield, Oxford 1998.

Hupa A., Badania orientacji politycznych w Internecie, „Studia Socjologiczne” 2007, vol. 186, nr 3.

Izdebski Z., Seks Polaków w Internecie. Raport Polpharmy 2010, Centrum Badań Marketingowych Indicator na zlecenie Polpharmy, http://www.opzs.pl/uploads/assets/files/Seks_Polakow_w_Internecie_prezentacja.pdf.

Kozinets R. V., Netnography. Doing Ethnographic Research Online, Sage Publications, Los Angeles 2010.

Kubczak A., Cybersocjologia? Internet jako przedmiot zainteresowania socjologów, w: Polskie doświadczenia w ksztaltowaniu spoleczeństwa informacyjnego: dylematy cywilizacyjno-kulturowe, Uczelniane Wydawnictwa Naukowo-Dydaktyczne AGH, Kraków 2002.

Lem S., Bomba megabitowa, Wydawnictwo Literackie, Kraków 1999.

Fiałkowski T., Lem S., Świat na krawędzi, Wydawnictwo Literackie, Kraków 2007.

Lyman P., Wakeford N., Going Into the (Virtual) Field, „American Behavioral Scientist” 1999, vol. 43, nr 3.

Lyon D., The Electronic Eye. The Rise of Surveillance Society, University of Minnesota Press, Minneapolis 1994.

Mącik R., Wykorzystanie Internetu w badaniach marketingowych, Wydawnictwo Uniwersytetu Marii Curie-Skłodowskiej, Lublin 2005.

Mann Ch., Stewart F., Internet Communication and Qualitative Research. A Handbook for Researching Online, Sage Publications, Londyn-New Delhi 2000.

Manovich L., Język nowych mediów, Wydawnictwa Akademickie i Profesjonalne, Warszawa 2006.

Margolis M., Resnick D., Tu Ch., Campaigning on the Internet: Parties and Candidates on the World Wide Web in the Primary Season, „Harvard International Journal of Press/Politics” 1997, vol. 2, nr 1.

$\mathrm{mn} / / \mathrm{mat} / \mathrm{k}$, Zrobili z niego „największego prostaka”. Pyta: Dlaczego ja?, „TVN24”, 8.08.2012, http://www.tvn24.pl/zrobili-z-niego-najwiekszego-prostaka-pyta-dlaczego-ja,269944,s.html.

Nikodemska-Wołowik A. M., Jakościowe badania marketingowe w Internecie-uzasadniony sceptycyzm, w: Marketing - koncepcje, badania, zarzqdzanie, red. L. Żabiński, K. Śliwińska, Wydawnictwo Naukowe PWN, Warszawa 2002.

Olcoń M., Zogniskowane wywiady grupowe online - charakterystyka techniki badawczej, w: Re: Internet-spoteczne aspekty medium, red. Ł. Jonak, P. Mazurek, M. Olcoń, A. Przybylska, A. Tarkowski, J. Zając, Wydawnictwa Akademickie i Profesjonalne, Warszawa 2006. 
Pant G., Srinivasan P., Menczer F., Crawling the Web, http://dollar.biz.uiowa.edu/ pant/Papers/crawling.pdf.

Park H. W., Hyperlink Network Analysis: A New Method for the Study of Social Structure on the Web, „Connections" 2003, vol. 25, nr 1.

Sawyer S., Rosenbaum H., Social Informatics in the Information Sciences: Current Activities and Emerging Directions, „Informing Science” 2000, vol. 3, nr 1.

Shenk D., Data Smog. Surviving the information glut, HarperCollins, Nowy Jork 1997.

Sobieszczek K., Problem błędu braku odpowiedzi w badaniach internetowych, w: Re: Internet-społeczne aspekty medium, red. Ł. Jonak, P. Mazurek, M. Olcoń, A. Przybylska, A. Tarkowski, J. Zając, Wydawnictwa Akademickie i Profesjonalne, Warszawa 2006.

Sobocińska M., Badania marketingowe. Teoria i praktyka, Wydawnictwo Naukowe PWN, Warszawa 2005.

Stone B., Politics '96, „Internet World” 1996.

Suler J. R., Identity Management in Cyberspace, „Journal of Applied Psychoanalytic Studies” 2002, nr 2.

Suler J. R., Presence in Cyberspace, 2003, http://users.rider.edu/ suler/psycyber/presence.html.

Suler J. R., The Basic Psychological Features of Cyberspace. Elements of a Cyberpsychology Model, 1996 (2002), http://users.rider.edu/ suler/psycyber/basicfeat.html.

Suler J. R., The First Decade of CyberPsychology, 2006, http://users.rider.edu/ suler/psycyber/decade.html.

Tadeusiewicz R., W dymie i we mgle..., „ComputerWorld” 1999, nr 37.

The Streisand Effect: When Internet Censorship Backfires, „Complex Pop Culture” 2009, http://www.complex.com/pop-culture/2009/07/the-streisand-effect-when-internet-censorship-backfires

Żmijewska-Jędrzejczyk T., Badania internetowe, w: Nowe metody, nowe podejścia badawcze w naukach społecz$n y c h$, red. P. Sztabiński, F. Sztabiński, Z. Sawiński, Wydawnictwo Instytutu Filozofii i Socjologii Polskiej Akademii Nauk, Warszawa 2004.

\section{Methodological dilemmas in studies on political culture in the Internet}

\section{Summary}

This paper concentrates on the analysis of methodological problems of studies conducted using the Internet, in particular on the issue of whether it is reasonable to apply classical research techniques. These considerations start with the reflection on the ontological parameters of the Internet: its physical, socio-psychological and information properties. Next, the paper analyzes four groups of research techniques: surveys of opinion, studies of behaviors, studies of cultural creations, and studies of the structure of the Internet. The subject of analyses involves the range and content of modifications required in order to apply individual research techniques in the Internet. 